\title{
An Exploratory Examination of Serious Surfers: Implications for the Surf Tourism Industry
}

\author{
SANDRA SOTOMAYOR ${ }^{1}$ and CARLA BARBIERI ${ }^{2 *}$ \\ ${ }^{1}$ Tourism Management Department, Universidad San Ignacio de Loyola, Lima, Peru \\ ${ }^{2}$ Department of Parks, Recreation and Tourism Management, North Carolina State University, Raleigh, NC, USA
}

\begin{abstract}
Surf tourism is a multibillion dollar industry expected to continue expanding. Despite such economic significance, the surf tourism literature has gaps related to surf tourism segments. In response, this study applied the serious leisure framework to profile serious surfers and contrast their sociodemographic composition and travel behaviors. Although more serious surfers are more avid travelers in the quest for the perfect wave as compared with less serious surfers, preference for local attractions and conveniences did not vary between groups. In addition to contributing the scholarship of serious leisure and surf tourism, this study provides insights for the surf tourism industry. Copyright (C) 2015 John Wiley \& Sons, Ltd.
\end{abstract}

Received 3 January 2014; Revised 25 November 2014; Accepted 19 December 2014

KEY WORDS destination preferences; serious leisure; surfing; surf tourism

\section{INTRODUCTION}

Surfboard riding, commonly referred as surfing, is practiced by millions and its popularity keeps increasing given the growing number of participants and a greater media attention at the recreational and the competitive levels (Farmer \& Short, 2007; Ponting, 2008; Frank, Zhou, Bezerra, \& Crowley, 2009; Ponting \& McDonald, 2013). Currently, surfing takes place in virtually every country with a coastline and expands to more locations every year (Tantamjarik, 2004; Ponting, 2008; Ponting \& McDonald, 2013). Because of technological advances such as more efficient and less expensive wetsuits, surfing is no longer an activity exclusive for those living in warm environments conducive to aquatic activities, but also suitable for those bearing with cold water conditions (Carrasco, 2008). The practice of surfing is expanding to tidal bores in rivers, activity that although started in the mid-seventies in Munich (Germany), is gaining popularity in other locations such as Quebec, Canada and Wyoming, US (Barrett, 2007).

Surfing has become a worldwide multibillion dollar industry that includes the sale of surf-branded clothing for surfers and non-surfers, the manufacture of surfboards and accessories, and surf-related travel costs (Buckley, 2002a, 2003). As a case in point, a market and non-market valuation of the surf industry in Bastion Point beach (Australia) was estimated in one quarter billion (Australian dollars) and about 20 billion in South Stradbroke Island (Lazarow, 2007). The rising consumption of surf-related gear (e.g., surfboards, wetsuits, traction pads and surf leashes) as well as accessories and surf-fashioned clothing associated with the growth of this recreational activity, have increased the supply and

\footnotetext{
*Correspondence to: Carla Barbieri, Department of Parks, Recreation and Tourism Management, North Carolina State University, Box 8004 3028D Biltmore Hall, Raleigh, NC 27695-8004, USA.

E-mail: carla_barbieri@ncsu.edu
}

prices of goods and services for surfers and followers of this activity (Buckley, 2003; Nourbakhsh, 2008). Although surfers demand surfing gear, the consumption of accessories is especially strong amongst fans (surf followers who do not surf) for whom certain brands and fashions convey their surfing identity (Moutinho et al., 2007) or a fashionable accessory amongst the public (Buckley, 2003).

Since Walker and colleagues' pioneer studies about Hawaiian surf breaks in the early 1970s (Scarfe et al., 2003), scientific research related to surfing has evolved within the recreation and tourism disciplines. A systematic review of the surf tourism literature from 1997 to 2011 (excluding travel sources, magazines, periodicals and websites) resulted in 156 documents, 42 of them published in scientific journals (Martin \& Assenov, 2012). Such review suggests a new but vibrant surf tourism research that not only has evolved in terms of quantity, but also in scope, moving from local descriptions to more in-depth comprehension of the surf tourism industry, usually highlighting sustainability implications. Yet, few studies have examined different market segments of the surfing industry (Booth, 1996; Ponting, 2009; Scarfe et al., 2009; Barbieri \& Sotomayor, 2013), especially to disclose travel behaviors and destination preferences across different types of surfers. Research is especially needed to explore whether surfers' behaviors and preferences differ amongst participants with different levels of surfing commitment, as differences amongst recreationists with different experience levels have been reported amongst other types of recreational activities (Scott \& Godbey, 1994; Cole \& Scott, 1999; Scott \& Lee, 2010).

Therefore, an exploratory study was conducted in 2010-2011 to investigate the implications of surfing as a serious leisure activity in travel behaviour amongst a group of surfers residing in the Americas, Asia and Europe. This manuscript specifically focuses on segmenting surfers based on the seriousness of their surfing involvement, to later compare 
travel behaviours and preferences for local attractions and conveniences in surf travel destinations between identified segments. This manuscript expands previous findings on this topic that evaluated the association between the six qualities of serious surfing and indicators of the surfing appeal (e.g., abundance of good waves) and infrastructure (e.g., on-site restroom facilities) of travel destinations (Barbieri \& Sotomayor, 2013). Study results can assist surfing tourism destinations and specialised surfing travel businesses in the development of advertising strategies targeting different types of clients within this lucrative tourism market.

\section{LITERATURE REVIEW}

The existing literature on surfing has covered a variety of topics, such as physiological and physical needs and preferences of surfers (Scarfe et al., 2003; Mendez-Villanueva \& Bishop, 2005; Buckley, 2012), activity profile of competitive surfing (Mendez-Villanueva, Bishop, \& Hammer, 2006), performance assessment across genders (Eurich, Brown, Coburn, Noffal, Nguyen, Khamoui \& Uribe, 2010), impacts of surfing events (Getz \& Fairley, 2003; O'Brien, 2007; Ahmed, Moodley, \& Sookrajh, 2008) and medical issues (e.g., injuries) related to this activity (Carrasco, 2008; Frank et al., 2009; Hay, Barton, \& Sulkin, 2009). An important piece of the literature has emphasised the managerial aspects of surfing, such as crowding and recreational carrying capacity (Buckley, 2002a, 2002b), and more recently conservation and sustainability issues (Tantamjarik, 2004; Farmer \& Short, 2007; Lazarow, 2007; Scarfe, 2008; Scarfe et al., 2009; O'Brien \& Ponting, 2013). Martin and Assenov (2012) point out that evaluating the marketing side of surfing has played a major role in the scientific development of surf tourism either by profiling the social actors of the surf industry (e.g., Buckley, 2002a,2002b; Dolnicar \& Fluker, 2003) or exploring the imaginary of surfing (e.g., Ponting, 2006, 2008, 2009; De Nardi \& Wilks, 2007). The following two sections summarise key studies on surfing related to the scope of this manuscript.

\section{Surfing within recreation and tourism studies}

Surfing is a unique recreational activity and differs from other sports mainly because competition against other individuals is not the main purpose; rather, the main challenger is the wave (Farmer, 1992; Tantamjarik, 2004; Buckley, 2012). However, competition with other surfers to catch the waves are reported in crowded situations or in areas with strong localism, where local surfers display territorialism over particular surf breaks or spaces (Scarfe et al., 2003; Walker, 2008; Alessi, 2009; Usher \& Kerstetter, 2013). There is also a psychological surf obsession amongst most surfers, which seems to be related to a change in the emotional state, from tension to calm, that surfers experience whilst surfing (Butts, 2001). When examined within the sport discipline, studies conclude that although surfers also seek health and fitness rewards as other athletes do, they have a different set of motivations than mainstream athletes; surfers are primarily driven by the exhilaration of the experience and seek catharsis and aesthetic rewards rather than competition (Farmer, 1992; Buckley, 2012). Consistent with participants of other risk-recreation activities, surfers have high levels of sensation seeking traits that include the constant search for varied, novel and complex sensations and experiences, especially for the thrill that this activity produces (Farmer, 1992; Stranger, 1999, 2011; Diehm \& Armatas, 2004; Ponting, 2008; Buckley, 2012).

In parallel with being an activity traditionally dominated by men, most of surfing related studies focus on male participants (Farmer, 1992; Butts, 2001; Moutinho et al., 2007). However, after the increase of women participating in surfing over the past several decades, Nourbakhsh (2008) conducted a series of interviews with nine female surfers from the California Central Coast to understand the phenomenological meanings and behaviours amongst female surfers and their transition from the general (novice) to the particular (advanced) ends of the recreation specialisation (i.e., skills and experience levels) continuum. This study found that past participation, perceived skills, commitment and enduring involvement were the most important emerging themes related to surf specialisation whilst initial attraction, initial motivation to participate or actively pursue, and enduring motivation were the themes related to motivations behind surf participation.

Less information is available on different types of surfers. Farmer (1992) reported that a surf shop manager operating in one of the Carolina's beaches identified five types of surfers. The rowdy bunch, mostly composed by novice surfers, whose main interest is to party with their surfer friends; the school boys for whom surfing was an after-school pastime; the weekend warriors who can only surf when they are out of work; the hard core who live and work near the coast for surfing purposes; and the beach bums who dedicate their lives exclusively to surfing.

Dolnicar and Fluker (2003) identified five segments of surfers in Australia with distinct demographic, surf-related preferences (e.g., type of waves and challenges) and travel behaviour. The radical adventurers, comprising the youngest surfers with the lowest income, were more concerned with the local culture and the surfing qualities of the destination in terms of the time of the surfing season, secret locations, lack of crowd and quality of the natural environment. The luxury surfers were more concerned with the service quality of the destination in terms of accommodations, food and safety whilst they were not bothered with the price or exchange rates. The price-conscious safety seekers, representing the oldest group with the most years involved in surfing and highest income, placed high importance on family facilities and the quality of accommodations. The price-conscious adventurers constantly searching for new locations and discoveries as well as the lack of crowds. Both price-conscious groups care about destination surfing conditions (e.g., surf seasonality), personal safety and health, and quality of meals. The study also identified a group of ambivalents who did not appear with any particular surfing or destination preference. More recently, Moutinho et al. (2007) conducted a qualitative study in Portugal focusing 
on the tribal/cult attributes of surfing. Although not the main purpose of their study, they reported that surfers recognise the existence of regular and occasional ones, the latter group also comprising non-surfers exhibiting a surfing image through a surf-dressing code.

Existing studies (Farmer, 1992; Dolnicar \& Fluker, 2003, 2004; Moutinho et al., 2007; Nourbakhsh, 2008) have provided strong evidence that surfers need to be differentiated on their travel behaviour, for example, profiling surfers who are more lucrative from the industry perspective. However, in developing psychographic-based profiles, previous studies have failed to fully capture whether associations between the surfing skill level and destinations preferences exist. For example, advanced surfers tend to be spread across most surf market segments identified, and all segments show a strong preference for lack of crowds at surfing destinations (Dolnicar \& Fluker, 2003). These results suggest that further attention is needed to explore destination preferences across different types of surfers, including those who are at different levels in the casual-serious continuum.

\section{Surfing within the serious leisure literature}

Serious leisure is the systematic pursuit of a leisure activity either as an amateur, hobbyist or volunteer that provides personal fulfilment, identity enhancement, self expression and other benefits to the participant (Stebbins, 1982, 1992). As compared with casual leisure, those engaged in serious leisure comprise six qualities: perseverance, career development, personal effort, durable benefits and strong identity with the activity, and unique ethos with their peers (Stebbins, 1982, 1992, 1999; Brown, 2007; Gould, Moore, McGuire, \& Stebbins, 2008). Most serious leisure studies have used qualitative methods to examine the attributes of several activities in-depth (e.g., Green \& Chalip, 1998; Jones, 2000; Gibson, Willming, \& Holdnak, 2002; Brown, 2007; Murray, 2009). More recently though, Gould et al. (2008) developed the serious leisure inventory and measure (SLIM) scale, a measurement instrument to quantitatively assess the construct of serious leisure.

The SLIM is composed of 54 operational items, organised in 18 subdimensions representing the six definitional qualities of serious leisure (Gould et al., 2008). Although serious leisure is usually defined by its six qualities, Stebbins (2001) conceptualised that some of those qualities were multidimensional, which the SLIM scale captures as follows. One subdimension depicts the following four qualities: perseverance, personal effort, strong identity, and unique ethos. The career development quality is defined by two subdimensions: career progress and career contingencies. Finally, 12 subdimensions define the durable benefits quality: personal enrichment, self actualization, self expressing abilities, individual self expression, self image, self gratification satisfaction, enjoyment, recreation, financial return, social attraction, group accomplishments and group maintenance.

Evidence suggests that surfing shares the six qualities that distinguish serious leisure from casual leisure. As for perseverance, Ponting (2008) states that the surfer must 'possess sufficient skill and knowledge to utilise the power of a wave for forward momentum, track at an angle across the face of a wave, and anticipate and respond to its changing contours' (p. 23). Mastering at least the basic skills of surfing will allow the surfer to be recognised by their peers, thus attaining ethos (Butts, 2001). Such shared surfing ethos is characterised by the embracement of a simplified and more casual lifestyle, an increased value for the environment and an acknowledgement or compliance of accepting a set of unwritten rules (Nourbakhsh, 2008). Personal effort is recognised by the social hurdles (e.g., cancelling personal plans when the waves are good, pass-up job opportunities to stay near the ocean) and physical risks (e.g., stings from jellyfish, being struck with a surfboard and hitting the ocean floor) that are associated with becoming a surfer (Butts, 2001; Buckley, 2012). Although moving up in the surfing ladder may be difficult because of the high technical skills and personal abilities that are required (Mendez-Villanueva \& Bishop, 2005), differentiation between novice surfers and their peers suggests a career development in this activity acquired with practice (Butts, 2001; Buckley, 2012; Scarfe et al., 2003). Some durable benefits have been associated with surfing including the gain of courage, invigoration rather than exhaustion and fitness (Nourbakhsh, 2008). Strong identity is also considered as an important level of extrinsic motivation for surfers, and 'it is present when the individual comes to value and judge the behaviour as important to the self, and performs it out of choice' (Diehm \& Armatas, 2004; p. 666).

More recently, Barbieri and Sotomayor (2013) built on those studies and investigated whether the six serious leisure qualities are associated with surf travel behaviour and destination preferences. They found that although surfers show high levels of serious leisure in their six qualities and a strong disposition for surf tourism, serious leisure qualities are not associated with surf travel behaviour. However, they concluded that serious leisure qualities do predict preferences related to the overall surfing appeal, the variety of waves, and the quality of the natural environment of the destination.

\section{RESEARCH METHODS}

This exploratory study used snowball sampling, a technique in which an initial list of participants is identified and they are asked to refer the study to others participants (Patton, 2002). The initial contact list, assembled by both researchers and their acquaintances, was composed of 52 surfers. Participation was not restricted to any minimum activity level (e.g., number of surfing hours) as to capture surfers along the serious surfing continuum. However, as the way the initial list was crafted, only individuals who surf on a regular basis were originally recruited, thus most likely overlooking occasional or random surfers. Although significant effort was placed to identify surfers residing in different countries, only participants from the Americas, Asia and Europe were initially identified and contacted.

An online survey instrument was developed to gather information about indicators of serious surfing and surf travel behaviour. The survey was administered in English and Spanish; it was first developed in English, then translated to 
Spanish, and finally back-translated by a third party to assure content consistency between both versions. Starting in October 2010, initially contacted surfers were emailed an invitation with an embedded link to the survey; the survey also asked initial participants to provide the electronic contact information of their surfing fellows. Up to three e-reminders were sent to non-respondents. The survey yielded $136 \mathrm{com}-$ pleted responses.

The survey queried participants about their surfing activity (e.g., how long they have been surfing and number of days per week they surf), surf travel behaviour (e.g., number, frequency, and duration of trips), preferences for surfing appeal and infrastructure of the destination (e.g., types of wave, food and beverage services) and availability of local services/conveniences and other attractions (e.g., family friendly conveniences, lodging, nightlife opportunities). Based on the literature reviewed (Buckley, 2002a, 2002b), the surfing trip was defined in the survey instrument as travelling for the main purpose of surfing to a place located at least $40 \mathrm{~km}$ (25 mi) away from home, where you overnight at least one night. Demographic information of participants was also collected. To enable examination of the income profile across respondents residing in countries with different economic realities, a six-point scale was constructed: I do not earn income yet; I hardly make it to live; I can afford basic needs; I live with some comfort; I am able to save some money monthly; income is not a problem for me.

As for examining surfing within the serious leisure continuum, participating surfers were asked about their perceptions of the role that surfing played in their lives using a 5-point Likert scale ( $1=$ 'Strongly Disagree'; $5=$ 'Strongly Agree').
Such perceptions were operationalised through eighteen SLIM items (Gould et al., 2008), one from each of the 18 subdimensions developed to represent the six serious leisure qualities. Original items were slightly reworded to reflect the surfing activity. Table 1 summarises the SLIM items assessed in this study using a code representing the six serious leisure qualities (q) and the 18 SLIM subdimensions (d). For example, 'I overcome difficulties in surfing by being persistent' was coded as $\mathrm{q} 1-\mathrm{d} 1$ as this item operationalizes the first SLIM subdimension (d1) representing perseverance, the first serious leisure quality (q1).

Sociodemographic, destination preferences and SLIM indicators amongst respondents were first examined through descriptive analyses. Given that serious leisure activities are better understood when their participants are dichotomized (Gibson et al., 2002), respondents were classified into two groups. The overall median point of the 18 SLIM indicators $(M d n=4.06)$ was used as a threshold to group respondents based on the seriousness of their surfing given the intertwined nature of the SLIM indicators. The groups were labelled as less serious $(n=64 ; 50.4 \%)$ and more serious $(n=63 ; 49.6 \%)$ surfers given their overall high rankings in the SLIM scale. A series of independent $t$-tests and chisquare tests $(p<0.10)$ were employed to contrast sociodemographic attributes, surf tourism behaviour and preferences of surf destination attributes in terms of local attractions and conveniences between study groups. Taking into consideration the sample size of both groups (over 50), the normality condition of the dependent variables (SLIM and destination indicators) was relaxed to favour higher power obtained with $t$-tests as compared with non-parametric

Table 1. Summary of the serious leisure inventory and measure items used to represent the 18 dimensions defining the six qualities of serious leisure

\begin{tabular}{|c|c|c|}
\hline \multicolumn{2}{|l|}{ SLIM Qualities (q) and dimensions (d) } & \multirow[t]{2}{*}{ Numeric expression and labels of operational items } \\
\hline q1-Perseverance & & \\
\hline d1-Perseverance & $\mathrm{q} 1-\mathrm{d} 1$ & I overcome difficulties in surfing by being persistent \\
\hline q2-Personal effort & & \\
\hline d2-Personal effort & $\mathrm{q} 2-\mathrm{d} 2$ & I practice to improve my surfing skills \\
\hline \multicolumn{3}{|l|}{ q3-Career development } \\
\hline d3-Career progress & q3-d3 & I have consistently improved since I started surfing \\
\hline d4-Career contingencies & $\mathrm{q} 3-\mathrm{d} 4$ & $\begin{array}{l}\text { Certain positive or negative surfing events } \\
\text { have influenced my surfing involvement }\end{array}$ \\
\hline \multicolumn{3}{|l|}{ q4-Durable benefits } \\
\hline d5-Personal enrichment & $\mathrm{q} 4-\mathrm{d} 5$ & Surfing had added richness to my life \\
\hline d6-Self actualization & q4-d6 & I make full use of my talent when surfing \\
\hline d7-Self expressing abilities & $\mathrm{q} 4-\mathrm{d} 7$ & Surfing is a way to display my skills and abilities \\
\hline d8-Individual self expression & $\mathrm{q} 4-\mathrm{d} 8$ & Surfing for me is an expression of myself \\
\hline d9-Self image & $\mathrm{q} 4-\mathrm{d} 9$ & Surfing has enhanced my self image \\
\hline d10-Self gratification satisfaction & $\mathrm{q} 4-\mathrm{d} 10$ & Surfing is intensively gratifying to me \\
\hline d11-Enjoyment & q4-d11 & I enjoy surfing \\
\hline d12-Recreation & $\mathrm{q} 4-\mathrm{d} 12$ & I feel renewed after surfing \\
\hline d13-Financial return & $\mathrm{q} 4-\mathrm{d} 13$ & I have been paid $(\$)$ for my surfing efforts \\
\hline d14-Social attraction & q4-d14 & I like interacting with other surfers \\
\hline d15-Group accomplishments & $\mathrm{q} 4-\mathrm{d} 15$ & The accomplishments of my surfing group are important to me \\
\hline d16-Group maintenance & $\mathrm{q} 4-\mathrm{d} 16$ & The development of my surfing group is important to me \\
\hline \multicolumn{3}{|l|}{ q5-Unique ethos } \\
\hline d17-Unique ethos & q5-d17 & I share the same way of thinking with other surfers \\
\hline \multicolumn{3}{|l|}{ q6-Strong identity } \\
\hline d18-Strong identity & q6-d18 & I am often recognised as a surfer \\
\hline
\end{tabular}

SLIM, serious leisure inventory and measure. 
Table 2. Region of residence, gender, age and country of residence of participating surfers

\begin{tabular}{|c|c|c|}
\hline Sociodemographic indicators & $n$ & $\%$ \\
\hline \multicolumn{3}{|c|}{ Residence by geographic region $(n=126)$} \\
\hline Pacific South America ${ }^{a}$ & 60 & $47.6 \%$ \\
\hline Continental US & 39 & $26.2 \%$ \\
\hline Atlantic South America ${ }^{b}$ & 13 & $10.3 \%$ \\
\hline Central America ${ }^{\mathrm{c}}$ & 12 & $9.5 \%$ \\
\hline Hawaii & 6 & $4.8 \%$ \\
\hline Other regions ${ }^{d}$ & 2 & $1.6 \%$ \\
\hline \multicolumn{3}{|l|}{ Gender $(n=126)$} \\
\hline Male & 110 & $87.3 \%$ \\
\hline Female & 16 & $12.7 \%$ \\
\hline \multicolumn{3}{|l|}{ Household composition $(n=125)$} \\
\hline Live alone at home & 29 & $23.2 \%$ \\
\hline Live with at least another person & 96 & $76.8 \%$ \\
\hline \multicolumn{3}{|c|}{ Respondents employment status $(n=127)^{\mathrm{e}}$} \\
\hline Full-time employee & 58 & $45.7 \%$ \\
\hline Part-time employee & 14 & $11.0 \%$ \\
\hline Self-employed & 45 & $35.4 \%$ \\
\hline Student & 20 & $15.7 \%$ \\
\hline Other ${ }^{\mathrm{f}}$ & 12 & $9.4 \%$ \\
\hline \multicolumn{3}{|l|}{ Current surfing involvement $(n=135)$} \\
\hline Currently surf & 128 & $94.8 \%$ \\
\hline Do not surf currently & 7 & $5.2 \%$ \\
\hline \multicolumn{3}{|l|}{ Time involved in surfing $(n=135)^{\mathrm{g}}$} \\
\hline Less than 2 years & 9 & $6.7 \%$ \\
\hline $2-5$ years & 12 & $8.9 \%$ \\
\hline $5-10$ years & 32 & $23.7 \%$ \\
\hline 10 years or more & 82 & $60.7 \%$ \\
\hline
\end{tabular}

${ }^{a}$ Includes respondents from Peru $(n=56)$ and Chile $(n=4)$.

${ }^{\mathrm{b}}$ Includes surfers from Argentina $(n=7)$, Venezuela $(n=4)$, Brazil $(n=1)$ and Uruguay $(n=1)$.

${ }^{\mathrm{c}}$ Central America includes respondents from Guatemala $(n=7)$, Jamaica $(n=2)$, Costa Rica $(n=1)$, Panama $(n=1)$ and Puerto Rico $(n=1)$.

${ }^{\mathrm{d}}$ Includes respondents from Australia $(n=1)$ and Japan $(n=1)$.

${ }^{e}$ Percentages sum to more than $100 \%$, as respondents were able to select multiple categories.

${ }^{\mathrm{f}}$ Others include the following: unemployed, homemaker and retired from a previous job or profession.

${ }^{\mathrm{g}}$ Measured on a 6-point scale ranging from 1 (less than 3 months) to 6 (10 years or more). tests (Casella \& Berger, 2002; Vaske, 2008). Bonferroni correction was used to reduce type II statistical error when performing multiple comparisons related to the SLIM dimensions $(0.10 / 18=p<0.006)$ and the destination attributes $(0.10 / 17=p<0.006)$.

\section{STUDY RESULTS}

\section{Respondents' demographics, serious surfing profile and destination preferences}

Responding surfers were from different geographic regions; the regions with higher representation were the Pacific South America (47.6\%) and the continental US (26.2\%; Table 2). The survey captured a large proportion of male surfers $(87.3 \%)$. Most participants were living with at least one other person at home $(76.8 \%)$, mostly with their spouse, partner or significant other, or other relatives or friends. A relatively large proportion of responding surfers were fulltime employees $(45.7 \%)$ or self-employed $(35.4 \%)$. Respondents were highly involved in surfing; $94.8 \%$ were current surfers, and most of those not currently surfing indicated that they were planning to surf again in the future. The majority $(60.7 \%)$ had at least 10 years of surfing experience, $23.7 \%$ had between 5 and 10 years of surfing experience, and only $15.6 \%$ had been involved in surfing for less than 5 years.

Responding surfers showed very high indicators of serious leisure, especially related to their overall SLIM score $(M=4.0 ; M d n=4.1$; Table 3). Most subdimensions were also over the neutral point, with the exception of financial return benefit, which score was below the neutrality point $(M=2.1$; $S D=1.3$ ). The very vast majority of respondents strongly agree that surfing is very beneficial to them in terms of enjoyment $(90.5 \% ; M=4.8 ; S D=0.6)$, recreation $(80.3 \% ; M=4.7$; $S D=0.7)$, self gratification satisfaction $(77.1 \% ; M=4.7$; $S D=0.7)$ and personal enrichment $(73.9 ; M=4.6 ; S D=0.6)$.

Table 3. Perceptions of surfing as serious leisure: An application of the serious leisure inventory and measure scale

\begin{tabular}{|c|c|c|c|c|c|c|c|c|c|}
\hline SLIM Dimensions (d) & $n$ & Strongly disagree & Disagree & Neutral & Agree & Strongly agree & $M^{\mathrm{a}}$ & $S D$ & $M d n^{\mathrm{a}}$ \\
\hline (q4-d11) Enjoyment & 127 & $1.6 \%$ & $0.8 \%$ & $0.0 \%$ & $7.1 \%$ & $90.5 \%$ & 4.8 & 0.6 & 5.0 \\
\hline (q4-d12) Recreation & 127 & $1.6 \%$ & $0.8 \%$ & $3.1 \%$ & $14.2 \%$ & $80.3 \%$ & 4.7 & 0.7 & 5.0 \\
\hline (q4-d10) Self gratification satisfaction & 127 & $1.6 \%$ & $0.8 \%$ & $0.0 \%$ & $20.5 \%$ & $77.1 \%$ & 4.7 & 0.7 & 5.0 \\
\hline (q4-d5) Personal enrichment & 127 & $1.6 \%$ & $1.6 \%$ & $2.4 \%$ & $20.5 \%$ & $73.9 \%$ & 4.6 & 0.6 & 5.0 \\
\hline (q1-d1) Perseverance & 127 & $1.6 \%$ & $1.6 \%$ & $6.3 \%$ & $44.9 \%$ & $45.6 \%$ & 4.3 & 0.8 & 4.0 \\
\hline (q2-d2) Personal effort & 124 & $0.8 \%$ & $1.6 \%$ & $12.9 \%$ & $37.1 \%$ & $47.6 \%$ & 4.3 & 0.8 & 4.0 \\
\hline (q4-d8) Individual self expression & 126 & $1.6 \%$ & $3.2 \%$ & $12.7 \%$ & $38.9 \%$ & $43.6 \%$ & 4.2 & 0.9 & 4.0 \\
\hline (q4-d14) Social attraction & 124 & $1.6 \%$ & $1.6 \%$ & $12.9 \%$ & $47.6 \%$ & $36.3 \%$ & 4.2 & 0.8 & 4.0 \\
\hline (q3-d3) Career progress & 126 & $0.8 \%$ & $4.8 \%$ & $16.7 \%$ & $36.5 \%$ & $41.2 \%$ & 4.1 & 0.9 & 4.0 \\
\hline (q4-d6) Self actualization & 126 & $0.8 \%$ & $3.2 \%$ & $23.8 \%$ & $37.3 \%$ & $34.9 \%$ & 4.0 & 0.9 & 4.0 \\
\hline (q4-d9) Self image & 125 & $1.6 \%$ & $4.0 \%$ & $23.2 \%$ & $36.8 \%$ & $34.4 \%$ & 4.0 & 0.9 & 4.0 \\
\hline (q5-d17) Unique ethos & 125 & $3.2 \%$ & $6.4 \%$ & $28.0 \%$ & $44.0 \%$ & $18.4 \%$ & 3.9 & 0.9 & 4.0 \\
\hline (q4-d16) Group maintenance & 127 & $3.9 \%$ & $3.9 \%$ & $21.3 \%$ & $44.1 \%$ & $26.8 \%$ & 3.9 & 0.9 & 4.0 \\
\hline (q6-d18) Strong identity & 125 & $3.2 \%$ & $7.2 \%$ & $27.2 \%$ & $36.8 \%$ & $25.6 \%$ & 3.7 & 1.0 & 4.0 \\
\hline (q3-d4) Career contingencies & 126 & $4.0 \%$ & $9.5 \%$ & $27.8 \%$ & $30.9 \%$ & $27.8 \%$ & 3.7 & 1.1 & 4.0 \\
\hline (q4-d15) Group accomplishments & 127 & $5.5 \%$ & $4.0 \%$ & $30.7 \%$ & $30.7 \%$ & $29.1 \%$ & 3.7 & 1.1 & 4.0 \\
\hline (q4-d7) Self expressing abilities & 125 & $1.6 \%$ & $8.0 \%$ & $40.8 \%$ & $27.2 \%$ & $22.4 \%$ & 3.6 & 0.9 & 3.0 \\
\hline (q4-d13) Benefits - financial return & 125 & $45.6 \%$ & $19.2 \%$ & $16.8 \%$ & $12.0 \%$ & $6.4 \%$ & 2.1 & 1.3 & 2.0 \\
\hline Overall SLIM score & 127 & & & & & & 4.0 & 0.6 & 4.1 \\
\hline
\end{tabular}

SLIM, serious leisure inventory and measure.

${ }^{\mathrm{a}}$ Measured on a 5-point scale ranging from 1 (strongly disagree) to 5 (strongly agree). 
At the same time, about half of the respondents strongly agreed that surfing requires perseverance $(45.6 \% ; M=4.3$; $S D=0.8)$ and personal effort $(47.6 \% ; M=4.3 ; S D=0.8)$ to improve their skills. Although still showing high scores, the unique ethos $(M=3.9 ; S D=0.9)$ and the strong identity $(M=3.7 ; S D=1.0)$ usually associated with surfing did not appear as top qualities respondents perceive from surfing.

Cronbach's tests show high internal reliability amongst the items used to evaluate the importance of local attractions $(\alpha=0.885)$ and services and conveniences $(\alpha=0.851)$ when choosing a destination for surf tourism (Table 4). Overall, responding surfers perceive that local services and conveniences $(M=3.4 ; S D=0.7)$ are more important than attractions $(M=2.7 ; S D=0.9)$ when choosing a surf tourism destination. Regarding local attractions, having the surf destination natural sites close by was the only attribute considered over the neutral point $(M=3.2 ; S D=1.2)$. Most responding surfers indicated that several conveniences of the site were important when choosing their surf travel destination, including the appropriate surfing season $(82.8 \%$; $M=4.2 ; S D=0.9)$, price $(75.8 \% ; M=3.9 ; S D=0.9)$, safety in terms of low crime $(67.8 \% ; M=3.8 ; S D=1.1)$ and health concerns $(60.9 \% ; M=3.7 ; S D=1.1)$. Basic lodging $(68.7 \%$; $M=3.8 ; S D=0.9)$ also appeared important when choosing a surf travel destination. Respondents cared little about luxurious accommodations $(M=2.1 ; S D=1.1)$ and closeness to home $(M=2.8 ; S D=1.1)$.

\section{Profiling the serious surfers: demographic attributes and the seriousness of their surfing}

No significant differences on the sociodemographic characteristics between less serious and more serious surfers were found (Table 5). On average, both types of serious surfers were in their mid-30s, and about a quarter live alone.
Results also showed similar income distribution and relative high incomes between groups; the majority of less serious and more serious surfers indicated living with some comfort $(32.1 \%$ and $35.7 \%$, respectively), being able to save some money on monthly basis $(33.9 \%$ and $32.1 \%$, respectively), or not having an income problem $(5.7 \%$ and $14.3 \%$, respectively). However, significant differences between both groups on some indicators of the seriousness of their surfing activities were found. On average, less serious surfers reported surfing about half day less per week $(M=3.2$ days $)$ than serious surfers $(M=4.0$ days; $t=-2.716, p=0.008)$. The proportion of more serious surfers $(39.7 \%)$ with some sort of surf-related income was over two-fold more than amongst less serious surfers $\left(17.5 \% ; x^{2}=7.622 ; p=0.005\right)$.

Statistical tests showed that overall SLIM scores $\left(M_{\text {less }}=3.6 ; M_{\text {more }}=4.4 ; t=-10.283 ; p<0.001\right)$, as well as all serious leisure qualities were significantly stronger amongst more serious surfers as compared with their less serious counterparts (Table 6). In spite of such differences, high scores amongst both groups were equally observed in the enjoyment $\left(M_{\text {less }}=4.7 ; M_{\text {more }}=5.0 ; t=-3.000 ; p=0.004\right)$, recreation $\left(M_{\text {less }}=4.5 ; M_{\text {more }}=4.9 ; t=-3.199 ; p=0.002\right)$, self gratification satisfaction $\left(M_{\text {less }}=4.5 ; \quad M_{\text {more }}=4.9\right.$; $t=-3.749 ; p<0.001)$ and personal enrichment $\left(M_{\text {less }}=4.4\right.$; $M_{\text {more }}=4.9 ; t=-4.249 ; p<0.001$ ) associated with surfing. It is worth noting that less serious surfers had neutral perceptions about the existence of a surfing community in terms of group maintenance $\left(M_{\text {less }}=3.3 ; M_{\text {more }}=4.4 ; t=-6.939\right.$; $p<0.001)$, group accomplishments $\left(M_{\text {less }}=3.2 ; \quad M_{\text {more }}=4.3\right.$; $t=-6.665 ; p<0.001)$, unique ethos $\left(M_{\text {less }}=3.4 ; M_{\text {more }}=4.0 ; t=\right.$ -3.274; $p=0.001)$, strong identity $\left(M_{\text {less }}=3.3 ; M_{\text {more }}=4.2 ; t=\right.$ $-5.704 ; \quad p<0.001)$, career contingencies $\left(M_{\text {less }}=3.3\right.$; $\left.M_{\text {more }}=4.1 ; t=-4.636 ; p<0.001\right)$, and a self expressing

Table 4. The perceived importance of destination attractions and conveniences amongst responding surfers

\begin{tabular}{|c|c|c|c|c|c|c|c|c|}
\hline Destination attributes ${ }^{\text {a }}$ & $n$ & Very unimportant & Unimportant & Neutral & Important & Very important & $M^{\mathrm{b}}$ & $S D$ \\
\hline \multicolumn{9}{|l|}{ Attractions $(\alpha=0.885)$} \\
\hline Closeness to natural sites & 115 & $11.3 \%$ & $11.3 \%$ & $33.0 \%$ & $30.4 \%$ & $14.0 \%$ & 3.2 & 1.2 \\
\hline Historic and cultural richness & 115 & $20.9 \%$ & $23.5 \%$ & $21.7 \%$ & $29.6 \%$ & $4.3 \%$ & 2.7 & 1.2 \\
\hline Availability of non-water sports & 115 & $20.0 \%$ & $23.5 \%$ & $31.3 \%$ & $17.4 \%$ & $7.8 \%$ & 2.7 & 1.2 \\
\hline Availability of other water sports & 115 & $21.7 \%$ & $18.3 \%$ & $38.3 \%$ & $13.9 \%$ & $7.8 \%$ & 2.7 & 1.2 \\
\hline Surfing tournaments or events & 116 & $27.6 \%$ & $18.1 \%$ & $26.7 \%$ & $16.4 \%$ & $11.2 \%$ & 2.7 & 1.3 \\
\hline Nightlife options & 116 & $19.8 \%$ & $26.7 \%$ & $36.2 \%$ & $11.2 \%$ & $6.1 \%$ & 2.6 & 1.1 \\
\hline Man-made attractions & 115 & $39.1 \%$ & $26.1 \%$ & $23.5 \%$ & $5.2 \%$ & $6.1 \%$ & 2.1 & 1.2 \\
\hline Overall attractions mean & & & & & & & 2.7 & 0.9 \\
\hline \multicolumn{9}{|l|}{ Services and conveniences $(\alpha=0.851)$} \\
\hline Ideal surfing season & 116 & $1.7 \%$ & $4.3 \%$ & $11.2 \%$ & $38.8 \%$ & $44.0 \%$ & 4.2 & 0.9 \\
\hline Price opportunity & 116 & $2.7 \%$ & $6.0 \%$ & $15.5 \%$ & $53.4 \%$ & $22.4 \%$ & 3.9 & 0.9 \\
\hline Low crime risk area & 115 & $4.4 \%$ & $8.7 \%$ & $19.1 \%$ & $39.1 \%$ & $28.7 \%$ & 3.8 & 1.1 \\
\hline Basic lodging and accommodation & 115 & $2.6 \%$ & $6.1 \%$ & $22.6 \%$ & $47.8 \%$ & $20.9 \%$ & 3.8 & 0.9 \\
\hline Low health concern area & 115 & $5.2 \%$ & $5.2 \%$ & $28.7 \%$ & $36.5 \%$ & $24.4 \%$ & 3.7 & 1.1 \\
\hline Good place to gather with friends & 117 & $11.1 \%$ & $12.0 \%$ & $29.1 \%$ & $29.1 \%$ & $18.7 \%$ & 3.3 & 1.2 \\
\hline Family friendly facilities & 114 & $17.5 \%$ & $18.4 \%$ & $25.4 \%$ & $26.3 \%$ & $12.4 \%$ & 3.0 & 1.3 \\
\hline Friends and family living there & 116 & $16.4 \%$ & $19.8 \%$ & $32.8 \%$ & $20.7 \%$ & $10.3 \%$ & 2.9 & 1.2 \\
\hline Closeness to home & 115 & $14.8 \%$ & $23.5 \%$ & $35.6 \%$ & $18.3 \%$ & $7.8 \%$ & 2.8 & 1.1 \\
\hline Luxurious accommodations & 114 & $37.7 \%$ & $29.8 \%$ & $21.9 \%$ & $6.1 \%$ & $4.5 \%$ & 2.1 & 1.1 \\
\hline Overall conveniences mean & & & & & & & 3.4 & 0.7 \\
\hline
\end{tabular}

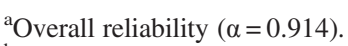

${ }^{\mathrm{b}}$ Measured on a five-point scale ranging from 1 (very unimportant) to 5 (very important). 
Table 5. A comparison of sociodemographic characteristics and indicators of surfing involvement between less serious and more serious surfers

\begin{tabular}{|c|c|c|c|c|}
\hline Socioeconomic indicators & Less serious surfers & More serious surfers & \multicolumn{2}{|c|}{ Statistical values } \\
\hline Average age (in years) & 34.8 & 35.7 & $t=-0.449$ & $p=0.655$ \\
\hline $\begin{array}{l}\text { Household composition }(n=118) \\
\text { Live alone } \\
\text { Live with at least another person }\end{array}$ & $\begin{array}{l}19.0 \% \\
81.0 \%\end{array}$ & $\begin{array}{l}26.7 \% \\
73.3 \%\end{array}$ & $x^{2}=0.991$ & $p=0.219$ \\
\hline $\begin{array}{l}\text { Household income level a }(n=109) \\
\text { I hardly make it to live } \\
\text { I can afford basic needs } \\
\text { I live with some comfort } \\
\text { I am able to save some money monthly } \\
\text { Income is not a problem for me }\end{array}$ & $\begin{array}{r}7.5 \% \\
20.8 \% \\
32.1 \% \\
33.9 \% \\
5.7 \%\end{array}$ & $\begin{array}{r}7.2 \% \\
10.7 \% \\
35.7 \% \\
32.1 \% \\
14.3 \%\end{array}$ & $x^{2}=3.907$ & $p=0.419$ \\
\hline $\begin{array}{l}\text { Number of days per week respondents surf }(n=126) \\
\text { Surfing days per week (mean) }\end{array}$ & 3.2 & 4.0 & $t=-2.716$ & $p=0.008^{*}$ \\
\hline $\begin{array}{l}\text { Surf related income }(n=126) \\
\text { Have some sort of surf-related income } \\
\text { Do not have any sort of surf-related income }\end{array}$ & $\begin{array}{l}17.5 \% \\
82.5 \%\end{array}$ & $\begin{array}{l}39.7 \% \\
60.3 \%\end{array}$ & $x^{2}=7.622$ & $p=0.005^{*}$ \\
\hline
\end{tabular}

Those not earning income yet $(n=10 ; 8.4 \%)$ were excluded

${ }^{\mathrm{b}}$ Statistically significant $(p<0.10)$.

Table 6. Comparing perceptions of surfing as serious leisure between less serious and more serious surfers ${ }^{\text {a }}$

\begin{tabular}{|c|c|c|c|c|c|}
\hline \multirow{2}{*}{$\frac{\text { SLIM dimensions }(n=127)}{\text { (q4-d11) Enjoyment }}$} & \multirow{2}{*}{$\frac{n}{127}$} & \multirow{2}{*}{$\frac{\text { Less serious surfers }}{4.7}$} & \multirow{2}{*}{$\frac{\text { More serious surfers }}{5.0}$} & \multicolumn{2}{|c|}{ Statistical values ${ }^{b}$} \\
\hline & & & & $t=-3.000$ & $p=0.004^{*}$ \\
\hline (q4-d12) Recreation & 127 & 4.5 & 4.9 & $t=-3.199$ & $p=0.002 *$ \\
\hline (q4-d10) Self gratification satisfaction & 127 & 4.5 & 4.9 & $t=-3.749$ & $p<0.001^{*}$ \\
\hline (q4-d5) Personal enrichment & 127 & 4.4 & 4.9 & $t=-4.249$ & $p<0.001^{*}$ \\
\hline (q1-d1) Perseverance & 127 & 4.0 & 4.6 & $t=-4.615$ & $p<0.001 *$ \\
\hline (q2-d2) Personal effort & 124 & 4.0 & 4.6 & $t=-4.590$ & $p<0.001 *$ \\
\hline (q4-d8) Individual self expression & 126 & 3.8 & 4.6 & $t=-6.257$ & $p<0.001^{*}$ \\
\hline (q4-d14) Social attraction & 124 & 3.8 & 4.6 & $t=-6.041$ & $p<0.001^{*}$ \\
\hline (q3-d3) Career progress & 126 & 3.7 & 4.6 & $t=-6.546$ & $p<0.001^{*}$ \\
\hline (q4-d6) Self actualization & 126 & 3.5 & 4.5 & $t=-7.974$ & $p<0.001^{*}$ \\
\hline (q4-d9) Self image & 125 & 3.5 & 4.4 & $t=-6.032$ & $p<0.001^{*}$ \\
\hline (q5-d17) Unique ethos & 125 & 3.4 & 4.0 & $t=-3.274$ & $p=0.001^{*}$ \\
\hline (q4-d16) Group maintenance & 127 & 3.3 & 4.4 & $t=-6.939$ & $p<0.001^{*}$ \\
\hline (q6-d18) Strong identity & 125 & 3.3 & 4.2 & $t=-5.704$ & $p<0.001^{*}$ \\
\hline (q3-d4) Career contingencies & 126 & 3.3 & 4.1 & $t=-4.636$ & $p<0.001^{*}$ \\
\hline (q4-d15) Group accomplishments & 127 & 3.2 & 4.3 & $t=-6.665$ & $p<0.001^{*}$ \\
\hline (q4-d7) Self expressing abilities & 125 & 3.2 & 4.1 & $t=-5.589$ & $p<0.001^{*}$ \\
\hline (q4-d13) Benefits - financial return & 125 & 1.8 & 2.6 & $t=-3.626$ & $p<0.001^{*}$ \\
\hline Overall SLIM score & 127 & 3.6 & 4.4 & $t=-10.283$ & $p<0.001^{*}$ \\
\hline
\end{tabular}

SLIM, serious leisure inventory and measure.

${ }^{a}$ Measured on a 5-point scale ranging from 1 (strongly disagree) to 5 (strongly agree).

'Overall MANOVA: $F=8.447 ; p<0.001$

*Statistically significant with Bonferroni adjusted critical value $(p<0.006)$

abilities $\left(M_{\text {less }}=3.2 ; M_{\text {more }}=4.1 ; t=-5.589 ; p<0.001\right)$ as compared with more serious surfers who agreed with those qualities.

\section{Surf travel behaviour and destination preferences amongst serious surfers}

Results showed that less serious and more serious surfers differed on their surfing travel behaviour (Table 7). Although a very large proportion of all responding surfers had taken at least one overnight trip with the main purpose of surfing in the past, such proportion was significantly larger amongst more serious $(96.8 \%)$ as compared with less serious $(84.1 \%) \quad$ surfers $\left(x^{2}=5.895 ; p=0.015\right)$. In a similar vein, more serious surfers travelled more often $\left(x^{2}=11.930 ; p=0.018\right)$ and were more willing to embark into surf tourism in the future $\left(x^{2}=13.678 ; p=0.001\right)$ than less serious surfers. Significant differences were also found on the significance of the quest for the perfect wave between both groups. Specifically, a larger proportion of more serious surfers, as compared with less serious surfers stated that abundance of good waves (less serious $=52.1 \%$; more serious $\left.=85.0 \% ; x^{2}=14.857 ; p<0.001\right)$, variety of wave types (less serious $=20.4 \%$; more serious $=50.9 \%$; $x^{2}=10.167 ; p=0.001$ ) and special types of waves (less 
Table 7. A comparison of surf tourism behaviour and preferred information sources between less serious and more serious surfers

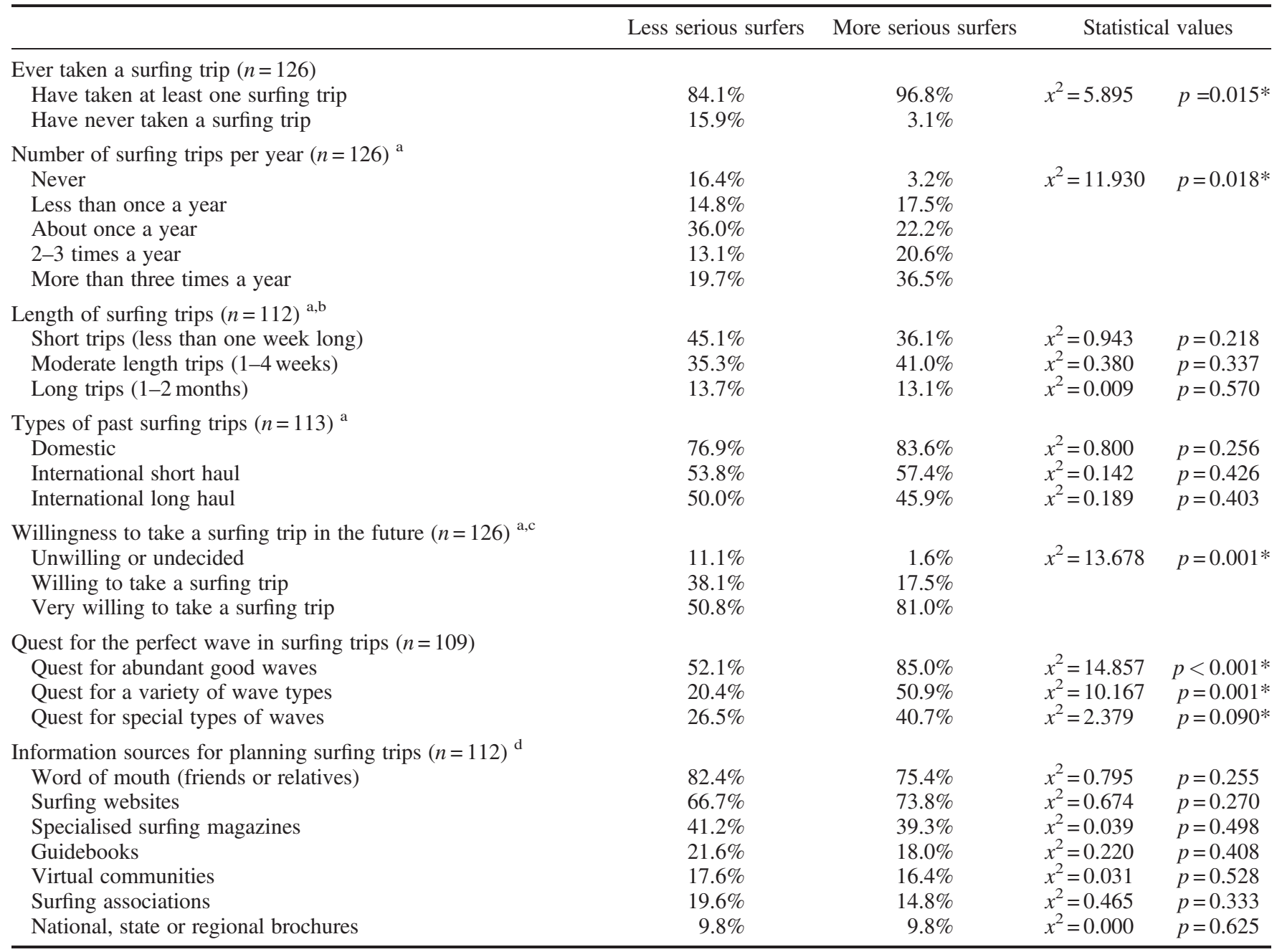

${ }^{\text {a }}$ This only includes those who have ever taken a surfing trip $(n=123 ; 90.4 \%)$.

${ }^{\mathrm{b}}$ Respondents were able to select multiple categories.

${ }^{\mathrm{c} O r i g i n a l l y ~ m e a s u r e d ~ o n ~ a ~ f i v e-p o i n t ~ s c a l e ~ r a n g i n g ~ f r o m ~} 1$ (very unwilling) to 5 (very willing).

${ }^{\mathrm{d} O n l y}$ response categories with more than $10 \%$ are reported.

*Statistically significant $(p<0.010)$

serious $=26.5 \%$; more serious $\left.=40.7 \% ; x^{2}=2.379 ; p<0.090\right)$ are very important drivers when choosing a surf travel destination

No statistical differences between less serious and serious surfers were found between the length of their surfing trips and the location of their destinations. A similar proportion within groups take short surfing trips (less serious $=45.1 \%$; more serious $=36.1 \%$ ), not quite as short surfing trips (less serious $=35.3 \%$; more serious $=41.0 \%$ ) and even those lasting one or two months (less serious $=13.7 \%$; more serious $=13.1 \%$ ). Respondents travelled for surfing to destinations within their country of residence (domestic) and abroad, both short haul and long haul, with no differences between less serious $(76.9 \%, 53.8 \%$, and $50.0 \%$, respectively) and more serious $(83.6 \%, 57.4 \%$, and $45.9 \%$, respectively) surfers.

With no significant differences between groups, word of mouth from friends or relatives and surfing websites appeared as the information sources that the majority of responding less serious $(82.4 \%$ and $66.7 \%$, respectively) and more serious $(75.4 \% ; 73.8 \%$, respectively) surfers sought out to plan their surfing trips. Also high, although to a lesser extent, the proportion of less serious (41.2\%) and more serious $(39.3 \%)$ surfers searching for surf travel information in specialised surfing magazines was statistically similar. The relevance of brochures as a source of information was very limited amongst both types of surfers (less serious $=9.8 \%$; more serious $=9.8 \%$ ), which may be related to the societal shift from printed to non-printed marketing channels and materials.

Although not statistically significant, less serious surfers cared less about local attractions than their counterparts $\left(M_{\text {less }}=2.6 ; M_{\text {more }}=2.8\right)$ when choosing a surf travel destination (Table 8). Both groups also reported similar neutrality and even indifference towards different types of attractions. More serious surfers expressed somewhat more importance $(M=3.6)$ towards services and conveniences that the site offers as compared with less serious surfers $(M=3.2)$, although such a difference was not significant. An ideal surfing season $\left(M_{\text {less }}=4.0 ; M_{\text {more }}=4.4\right)$, price $\left(M_{\text {less }}=3.8 ; M_{\text {more }}=4.0\right)$, low crime $\left(M_{\text {less }}=3.6 ; M_{\text {more }}=4.0\right)$, basic lodging and accommodations $\left(M_{\text {less }}=3.6 ; M_{\text {more }}=4.0\right)$ and low health concerns $\left(M_{\text {less }}=3.5 ; M_{\text {more }}=3.9\right)$ in the destination were important 
Table 8. A comparison of the perceived importance of destination attractions and conveniences between less serious and more serious surfers

\begin{tabular}{|c|c|c|c|c|c|}
\hline \multirow{2}{*}{$\frac{\text { Destination attributes }^{\text {a }}}{\text { Local attractions }(\alpha=0.885)}$} & \multirow[t]{2}{*}{$n$} & \multirow[t]{2}{*}{ Less serious surfers } & \multirow[t]{2}{*}{ More serious surfers } & \multicolumn{2}{|c|}{ Statistical values ${ }^{\mathrm{b}}$} \\
\hline & & & & & \\
\hline Closeness to natural sites & 107 & 3.3 & 3.3 & $t=-0.080$ & $p=0.936$ \\
\hline Historic and cultural richness of the site & 107 & 2.7 & 2.9 & $t=-0.661$ & $p=0.510$ \\
\hline Availability of non-water sports & 107 & 2.6 & 2.9 & $t=-1.113$ & $p=0.268$ \\
\hline Availability of other water sports & 107 & 2.7 & 2.7 & $t=-0.284$ & $p=0.777$ \\
\hline Surfing tournaments or events & 108 & 2.4 & 2.9 & $t=-1.899$ & $p=0.060$ \\
\hline Nightlife options & 108 & 2.5 & 2.7 & $t=-0.888$ & $p=0.376$ \\
\hline Man-made attractions & 107 & 1.9 & 2.4 & $t=-2.300$ & $p=0.023$ \\
\hline Overall attractions mean & 109 & 2.6 & 2.8 & $t=-1.553$ & $p=0.124$ \\
\hline \multicolumn{6}{|l|}{ Services and conveniences $(\alpha=0.851)$} \\
\hline Ideal surfing season in the destination & 108 & 4.0 & 4.4 & $t=-2.433$ & $p=0.017$ \\
\hline Price opportunity & 108 & 3.8 & 4.0 & $t=-1.252$ & $p=0.213$ \\
\hline Low crime risk area & 107 & 3.6 & 4.0 & $t=-1.631$ & $p=0.106$ \\
\hline Basic lodging and accommodation & 107 & 3.6 & 4.0 & $t=-2.009$ & $p=0.047$ \\
\hline Low health concern area & 107 & 3.5 & 3.9 & $t=-1.500$ & $p=0.137$ \\
\hline Good place to gather with friends & 109 & 3.2 & 3.6 & $t=-1.758$ & $p=0.082$ \\
\hline Family friendly facilities & 106 & 2.8 & 3.3 & $t=-2.050$ & $p=0.043$ \\
\hline Friends and family living there & 108 & 2.7 & 3.2 & $t=-2.417$ & $p=0.017$ \\
\hline Closeness to home & 108 & 2.9 & 2.9 & $t=-0.060$ & $p=0.953$ \\
\hline Luxurious accommodations & 106 & 2.0 & 2.2 & $t=-1.027$ & $p=0.307$ \\
\hline Overall conveniences mean & 109 & 3.2 & 3.6 & $t=-2.508$ & $p=0.014$ \\
\hline
\end{tabular}

${ }^{\mathrm{a}}$ Measured on a 5-point scale ranging from 1 (very unimportant) to 5 (very important).

${ }^{\mathrm{b}}$ Bonferroni adjusted critical value: $p<0.006$.

for all respondents with no statistical differences between groups. Being a good place to gather with friends $\left(M_{\text {less }}=3.2\right.$; $M_{\text {more }}=3.6$ ) was to some extent important for the more serious surfers but not important for their counterparts.

\section{DISCUSSION AND IMPLICATIONS}

Coastal destinations may choose, depending on their existing resources and strategies, to welcome any type of surfer or a group of surfers with certain characteristics (Dolnicar \& Fluker, 2003, 2004). Specifically, destinations with less unique surfing qualities may opt for not differentiating amongst surf travelers and even to appeal to those travelers seeking for a one-time surfing opportunity. In turn, destinations with strong surfing attributes (e.g., abundance of good waves and unspoiled surfing spots) may want to appeal to travelers more engaged in their surf as they are in constant quest for the perfect wave and surfing spot (Butts, 2001; Tantamjarik, 2004; Ponting, 2009; Barbieri \& Sotomayor, 2013; Ponting \& McDonald, 2013; Barbieri, Henderson, \& Santos, 2014). Study results identify attributes that coastal destinations can advertise to capture and cater to serious surfers. In doing so, it is important to recognise that although serious surfers emerged in this study as a great opportunity for surf tourism because they travel more in their quest for the perfect wave and reported relatively high incomes, it is yet to determine whether their travel expenditures differ from other types of surfers (e.g., casual surfers).

Local attractions, commonly used to advertise travel destinations, did not appear as strong pull tourism factors to capture serious surfers, which may be associated with surfers' avid search for the good surfing conditions (e.g., abundance of good waves and seclusion) as aforementioned. As per services and conveniences, destinations seeking to attract serious surfers should capitalise on their surfing season, local prices including basic lodging and accommodation, and safety (health and crime) as these were attributes equally important for all responding surfers. These results are somewhat consistent with the existing surfing literature; Dolnicar and Fluker (2003) found that most surfers consider crime and health as important destination elements, although surfing season and price did not appear as relevant. The prominence of an ideal surfing season as a pull factor for serious surfers, evidently favours destinations where year-round weather is conducive to surfing, thus should be capitalised on.

Study results suggest that market segmentation of surf travelers should move beyond their sociodemographic profile as no significant differences were found between both types of serious surfers. Instead, serious leisure appeared as suitable to distinct surfers on their surf travel behaviour, confirming the need to explore market segments based on their commitment to surf (Butts, 2001; Scarfe et al., 2003; Nourbakhsh, 2008; Buckley, 2012). In this sense, destinations willing to capture surfers who are closer to the serious end of the casual-serious continuum should appeal to the surfing identify (unique ethos and strong identity) and some durable benefits (group maintenance, group accomplishment and self expressing abilities) in their promotional campaigns. Conversely, more and less serious surfers do not appear to care differently on the services and conveniences available in the surfing destination. Yet, more research is needed to evaluate whether services and amenities do represent different meanings to those at the ends of the casual-serious surfing continuum, as found in other recreational activities (e.g., birdwatchers; Cole \& Scott, 1999), or to confirm whether preferences between casual and serious surfers do not exist as applicable to other recreational activities (Shen \& Yarnal, 2010).

Marketing campaigns are successful if they reach their target customers through appropriate channels. In this sense, it 
is imperative that surf destinations create a pleasant experience as word of mouth appeared to be the main reliable marketing source sought by less and more serious surfers alike. Providing surf-related information in the destination website as well as including advertising on specialised surfing magazines appeared pertinent as both are main marketing channels and are sought out for planning surfing trips confirming previous findings (Butts, 2001; Buckley, 2003). Strong perceptions about the surfing community (e.g., group maintenance, group accomplishments and strong surfing identity) found amongst the more serious surfers suggest that specialised social media such as blogs or online community networks may be effective surf tourism promotion channels, which calls for further investigation.

Although local services and conveniences appeared to have a greater role than local attractions when choosing a surf tourism destination, these results should be taken with caution as other factors not accounted for in this study may show different results. This study segmented surfers based on the seriousness of their surf, which may not necessarily reflect their surfing skills. Surfers with less or more advanced skills (e.g., balance, coordination and timing and ability to understand waves and currents), even amongst the serious surfers, may be looking for different surfing challenges (Buckley, 2012) or different types of waves in terms of height, peel angle, breaking intensity and length (Scarfe et al., 2003); seeking different challenges and waves may affect surfers' travel destination preferences, thus warranting further examination. The diversity of surf travel types in terms of length and destination amongst serious surfers suggests that future research investigates the pull factors of local attractions when travelling to long-haul lengthy trips as compared with shorter domestic ones given the different amount of time and money invested.

\section{CONCLUDING REMARKS}

This study contributes to the scholarship of serious leisure as a theoretical framework for recreational and tourism activities whilst providing marketing and management intelligence related to the practice of surf tourism. Being an exploratory study though, caution is advised to generalise results to all surfers, especially because of some limitations associated with how the sample was drawn. Although 136 responses are sufficient for exploratory studies like this one, participants do not necessarily represent the general perceptions of serious surfers. Likewise, although the intention was to recruit participants from different countries, surfers from certain popular surfing regions where under (e.g., Oceania) or not (e.g., Africa) represented. Finally, because study participants were recruited from an initial list of keen surfers and their referrals, the sample may be representing individuals towards the end of the casual-serious leisure continuum, as suggested by the relative large number of respondents having some sort of surf-related income. Taking into consideration the scholarly and practical contributions of this study, it is suggested that future studies control for the aforementioned study limitations and further scrutiny surfing within the entire casual-serious continuum.

From the scholarship perspective, results call for a further examination of some of the serious leisure qualities and the SLIM scale itself. Although indirect references to serious leisure qualities and the attainment of some durable benefits (Butts, 2001; Nourbakhsh, 2008; Ponting, 2008) were validated, the low scores associated with financial return benefit confirm that such quality should be taken as a participant trait rather than as a serious leisure predictor (Gould et al., 2008). Likewise, the unique ethos and strong identity usually associated with surfing (Butts, 2001; Diehm \& Armatas, 2004; Nourbakhsh, 2008) were not strongly present amongst participants, suggesting that those qualities may be stronger amongst surfing fans who tend to wear a certain dress code and gadgets to exteriorize their identity with the surfing community (Moutinho et al., 2007). On a similar line of thought, these results may also suggest that identity and ethos amongst surfers are subjacent to other qualities that actual surfers experience through surfing. Regarding the SLIM scale, it is suggested that new neutral statements are crafted to calibrate respondents' propensity to respond towards either end of the scale, as it may have happened in this study.

From the industry perspective, this study builds on previous studies identifying different types of surfers whose specific characteristics need to be accounted for to develop effective marketing strategies and maximise advertising results (Dolnicar \& Fluker, 2003, 2004; Moutinho et al., 2007; Barbieri \& Sotomayor, 2013). Specifically, study results provide marketing and management intelligence for surf tourism destinations wanting to capture serious surfers, which is critical when taking into consideration the billions of dollars generated by the surf industry (Lazarow, 2007; Moutinho et al., 2007; Nourbakhsh, 2008; Ponting, 2009). Besides the good quality of the waves (Ponting, 2008; Barbieri \& Sotomayor, 2013; Ponting \& McDonald, 2013; Barbieri et al., 2014), destinations willing to capture and cater to serious surfers should appeal to their capacity to reinforce surfer's individual and group identity, the suitability of their surfing season (e.g., year-round surfing season), their competitive prices and safety conditions.

\section{ACKNOWLEDGEMENTS}

The authors express their gratitude to the reviewers and journal editor for their thorough suggestions and comments. Thanks are also due to Dr. Seekamp, North Carolina State University, for her suggestions in an early version of the manuscript.

\section{REFERENCES}

Ahmed F, Moodley V, Sookrajh R. 2008. The environmental impacts of beach sport tourism events: A case study of the $\mathrm{Mr}$. Price Pro Surfing, Durban, South Africa. Africa Insight 38(3): $73-85$.

Alessi MD. 2009. The customs and culture of surfing, and an opportunity for a new territorialism? Reef Journal 1(1): 85-92. 
Barbieri C, Sotomayor S. 2013. Surf travel behavior and destination preferences: An application of the serious leisure inventory and measure. Tourism Management 35: 111-121.

Barbieri C, Henderson K, Santos C. 2014. Exploring memorable surfing trips. Annals of Tourism 48: 277-280.

Barrett P. 2007. Wai he'e nalu: From Polynesia to Munich, RiverSurfingCa, viewed 28 November, 2013, http://www. riversurfing.ca/about_riversurfing.php

Booth D. 1996. Surfing films and videos: Adolescent fun, alternative lifestyle, adventure industry. Journal of Sport History 23(3): 313-327.

Brown CA. 2007. The Carolina shaggers: Dance as serious leisure. Journal of Leisure Research 39(4): 623-647.

Buckley R. 2002a. Surf tourism and sustainable development in Indo Pacific Island - The industry and the islands. Journal of Sustainable Tourism 10(5): 405-424.

Buckley R. 2002b. Surf tourism and sustainable development in Indo Pacific Island - Recreational capacity management and case study. Journal of Sustainable Tourism 10(5): 425-442.

Buckley R. 2003. Adventure tourism and the clothing, fashion and entertainment industries. Journal of Ecotourism 2(2): 126-134.

Buckley R. 2012. Rush as a key motivation in skilled adventure tourism: Resolving the risk recreation paradox. Tourism Management 33: 961-970.

Butts S. 2001. Good to the last drop: Understanding surfers' motivations. Sociology of Sport Online, 4(1), viewed 6 January, 2011, http://www.physed.otago.ac.nz/sosol/v4i1/ v4i1butt.htm

Carrasco A. 2008. Effects of exercise-induced dehydration on cognitive ability, muscular endurance and surfing performance (Master's thesis). Massey University, Auckland, New Zealand.

Casella G, Berger RL. 2002. Statistical Inference (2nd ed). CENGAGE Learning: Stamford, CT.

Cole J, Scott D. 1999. Segmenting participation in wildlife watching: A comparison of casual wildlife watchers and serious birders. Human Dimensions of Wildlife 4(4): 44-61.

De Nardi M, Wilks J. 2007. Tourist water safety: Surf life saving initiatives for the Japanese inbound market. Journal of Vacation Marketing 13(3): 275-283.

Diehm R, Armatas C. 2004. Surfing: An avenue for socially acceptable risk-taking, satisfying needs for sensation seeking and experience seeking. Personality and Individual Differences 36: 663-677.

Dolnicar S, Fluker M. 2003. Who's riding the wave? An investigation into demographic and psychographic characteristics of surf tourists. Proceedings of the 13th International Research Conference of the Council for Australian University Tourism and Hospitality Education (CAUTHE).

Dolnicar S, Fluker M. 2004. The Symptomatic Nature of Past Destination Choice Among Surf Tourists. University of Wollongong: Faculty of Commerce - Papers.

Eurich A, Brown L, Coburn J, Noffal G, Nguyen D, Khamoui A, Uribe B. 2010. Performance differences between sexes in the pop-up phase of surfing. Journal of Strength \& Conditioning Research 24(10): 2821-2825.

Farmer R. 1992. Surfing motivations, values, and culture. Journal of Sport Behavior 15(3): 241-257.

Farmer B, Short A. 2007. Australian national surfing reserves - rationale and process for recognizing iconic surfing locations. Journal of Coastal Research 50: 99 - 103.

Frank M, Zhou S, Bezerra P, Crowley Z. 2009. Effects of long-term recreational surfing on control of force and posture in older surfers: A preliminary investigation. Journal of Exercise Science and Fitness 7(1): 31-38.

Getz D, Fairley S. 2003. Media management at sport events for destination promotion: Case studies and concepts. Event Management 8(3): 127-139.

Gibson H, Willming C, Holdnak A. 2002. "We're Gators... Not just Gator fans": Serious leisure and University of Florida football. Journal of Leisure Research 34(4): 397-425.
Gould J, Moore D, McGuire F, Stebbins R. 2008.Development of the serious leisure inventory and measure. Journal of Leisure Research 40(1): 47-68.

Green C, Chalip L. 1998. Sport tourism as the celebration of subculture. Annals of Tourism Research 25(2): 275-291.

Hay C, Barton S, Sulkin T. 2009. Recreational surfing injuries in Cornwall, United Kingdom. Wilderness and Environmental Medicine 20(4): 335-338.

Jones I. 2000. A model of serious leisure identification: the case of football fandom. Leisure Studies 19(4): 283-298.

Lazarow N. 2007. The value of coastal recreational resources: a case study approach to examine the value of recreational surfing to specific locales. Journal of Coastal Research 50 (Proceedings of the 9th International Coastal Symposium): 12-20.

Martin SA, Assenov I. 2012. The genesis of a new body of sport tourism literature: A systematic review of surf tourism research (1997-2011). Journal of Sport \& Tourism 17(4): 257-287.

Mendez-Villanueva A, Bishop D. 2005. Physiological aspects of surfboard riding performance. Sports Medicine 35(1): 55-70.

Mendez-Villanueva A, Bishop D, Hammer P. 2006. Activity profile of world-class professional surfers during competition: A case study. Journal of Strength \& Conditioning Research 20(3): 477-482.

Moutinho L, Dionısio P, Leal C. 2007. Surf tribal behaviour: A sports marketing application. Marketing Intelligence \& Planning 25(7): 668-690.

Murray D. 2009. Home brewing \& serious leisure an empirical evaluation (Master's thesis). Auburn University, Alabama.

Nourbakhsh T. 2008. A qualitative exploration of female surfers: recreation specialization, motivations, and perspectives (Master's thesis). California Polytechnic State University, San Luis Obispo, CA.

O'Brien D. 2007. Points of leverage: Maximizing host community benefit from a regional surfing festival. European Sport Management Quarterly 7(2): 141-165.

O’Brien D, \& Ponting J. 2013. Sustainable Surf Tourism: A Community Centered Approach in Papua New Guinea. Journal of Sport Management 27(2): 158-172.

Patton MQ. 2002. Qualitative Evaluation and Research Methods (3rd ed.). Sage Publications: Thousand Oaks, CA.

Ponting J. 2006. Castles made of sand: The 'Nirvanification' of the Mentawai Islands. International Tourism and Media (ITAM) Conference 2006.

Ponting J. 2008. Consuming Nirvana: An exploration of surfing tourist space (doctoral dissertation). University of Technology, Sydney.

Ponting J. 2009. Projecting paradise: The surf media and the hermeneutic circle in surfing tourism. Tourism Analysis 14(2): $175-185$.

Ponting J, McDonald M. 2013. Performance, agency and change in surfing tourist space. Annals of Tourism Research 43: 415-434.

Scarfe BE. 2008. Oceanographic considerations for the management and protection of surfing breaks. (Doctoral dissertation). University of Waikato, New Zealand.

Scarfe BE, Elwany MHS, Mead ST, Black KP. 2003. The science of surfing waves and surfing breaks - A review. Scripps Institution of Oceanography Technical Report, viewed November, 2014, https://escholarship.org/uc/item/6h72j1fz

Scarfe BE, Healy T, Rennie H, Mead S. 2009. Sustainable management of surfing breaks: Case studies and recommendations. Journal of Coastal Research 25(3): 684-703.

Scott D, Godbey G. 1994. Recreation specialization in the social world of Contact Bridge. Journal of Leisure Research 26(3): 275-295.

Scott D, Lee JH. 2010. Progression, stability or decline? Sociological mechanisms underlying change in specialization among birdwatchers. Leisure Sciences 32(2): 180-194.

Shen XS, Yarnal C. 2010. Blowing open the serious leisure-casual leisure dichotomy: What's in there? Leisure Sciences 32: 162-179. 
Stebbins R. 1982. Serious leisure: A conceptual statement. The Pacific Sociological Review 25(2): 251-272.

Stebbins R. 1992. Amateurs, Professionals, and Serious Leisure. McGill-Queen's University Press: Montreal.

Stebbins R. 1999. Serious leisure. In Leisure Studies: Prospects for the 21st Century, Jackson EL, Burton TL (eds). Venture Publishing: State College Pennsylvania; 69-78.

Stebbins R. 2001. New Directions in the Theory and Research of Serious Leisure. Edwin Mellen Press: Lewinston, NY.

Stranger M. 1999. The aesthetics of risk: A study of surfing. International Review for the Sociology of Sport 34(3): 265 - 276.

Stranger M. 2011. Surfing Life: Surface, Substructure and the Commodification of the Sublime. Ashgate Publishing: Surrey.
Tantamjarik P. 2004. Sustainability issues facing the costa Rica surf tourism industry (Master's thesis). University of Hawaii, HA.

Usher LD, Kerstetter D. 2013). An ethnographic study of surf tourism and localism in Nicaragua. Proceedings for the 44th Travel and Tourism Research Association Annual International Conference, viewed 24 November, 2014, http://tra. omnibooksonline.com/2013/54329-ttra-1.6558/2013-t-001-1.66 85/oral2-a-1.6730/oral2-a-1.6731

Vaske JJ. 2008. Survey Research and Analysis: Applications in Parks, Recreation and Human Dimensions. Venture Publishing Inc: State College, Pennsylvania.

Walker IH. 2008. Hui Nalu, Beachboys, and the surfing boarder-lands of Hawai'i. The Contemporary Pacific 20(1): 89-113. 